\title{
Immunosuppression in Glomerular Diseases: Implications for SARS-CoV-2 Vaccines and COVID-19
}

\author{
Michael R. Yeaman ${ }^{a, b, c}$ \\ ${ }^{a}$ Department of Medicine, David Geffen School of Medicine at UCLA, Los Angeles, CA, USA; ${ }^{b}$ Divisions of Molecular \\ Medicine \& Infectious Diseases, Harbor-UCLA Medical Center, Torrance, CA, USA; ${ }^{\top}$ The Lundquist Institute for \\ Biomedical Innovation at Harbor-UCLA Medical Center, Torrance, CA, USA
}

\section{Keywords}

Glomerular disease $\cdot$ Severe acute respiratory syndrome coronavirus 2 - Vaccine · Immunosuppression · Immunology

\begin{abstract}
Background: Glomerular diseases (GD) are chronic conditions that often involve immune dysfunction and require immunosuppressive therapy (IST) to control underlying pathogenesis. Unfortunately, such diseases appear to heighten risks of severe outcomes in COVID-19 and predispose to other infections that may be life-threatening. Thus, averting preventable infections is imperative in GD patients. Summary: The advent of vaccines demonstrated to be safe and efficacious against severe acute respiratory syndrome coronavirus 2 (SARS-CoV-2) has favorably impacted the COVID-19 pandemic epidemiology. However, patients on ISTs were excluded from initial vaccine clinical trials. Thus, only limited and incomplete data are available currently regarding the potential impact of immunosuppression on immune response to or efficacy of the SARS-CoV-2 vaccines. However, new insights are emerging from SARS-CoV-2 vaccine studies, and impacts of ISTs on conventional vaccines are useful to consider. Mechanisms of immunosuppressive agents commonly used in the treatment of GD are reviewed with respect
\end{abstract}

karger@karger.com www.karger.com/gdz

Karger"

BOPEN ACCESS
(C) 2021 The Author(s)

Published by S. Karger AG, Basel

This is an Open Access article licensed under the Creative Commons Attribution-NonCommercial-4.0 International License (CC BY-NC) (http://www.karger.com/Services/OpenAccessLicense), applicable to the online version of the article only. Usage and distribution for commercial purposes requires written permission. to implications for immune responses induced by SARS$\mathrm{CoV}-2$ vaccines. ISTs discussed include corticosteroids; alkylating agents; antimetabolites; calcineurin or mammalian target of rapamycin inhibitors; CD38+, CD20+, or CD19+ cell depletion; and complement protein C5 inhibition. Key Messages: Many immunosuppressive therapies may potentially attenuate or impair protective immunity of the SARS-CoV-2 vaccines. However, as vaccines currently in use employ mRNA or nonreplicative viral vectors, they appear to be safe in patients on immunosuppression, further favoring vaccination. Moreover, predominant SARS-CoV-2 vaccines are likely to afford at least partial protective immunity through one or more immune mechanisms even in patients on IST. Guidelines and emerging strategies are also considered to optimize vaccine protection from COVID-19.

(C) 2021 The Author(s).

Published by S. Karger AG, Basel

\section{Introduction}

Glomerular diseases (GD) are chronic, progressive, and debilitating conditions that may impose significant morbidity and mortality if unresponsive to treatment [1]. Treatments themselves, however, can also impose con- 


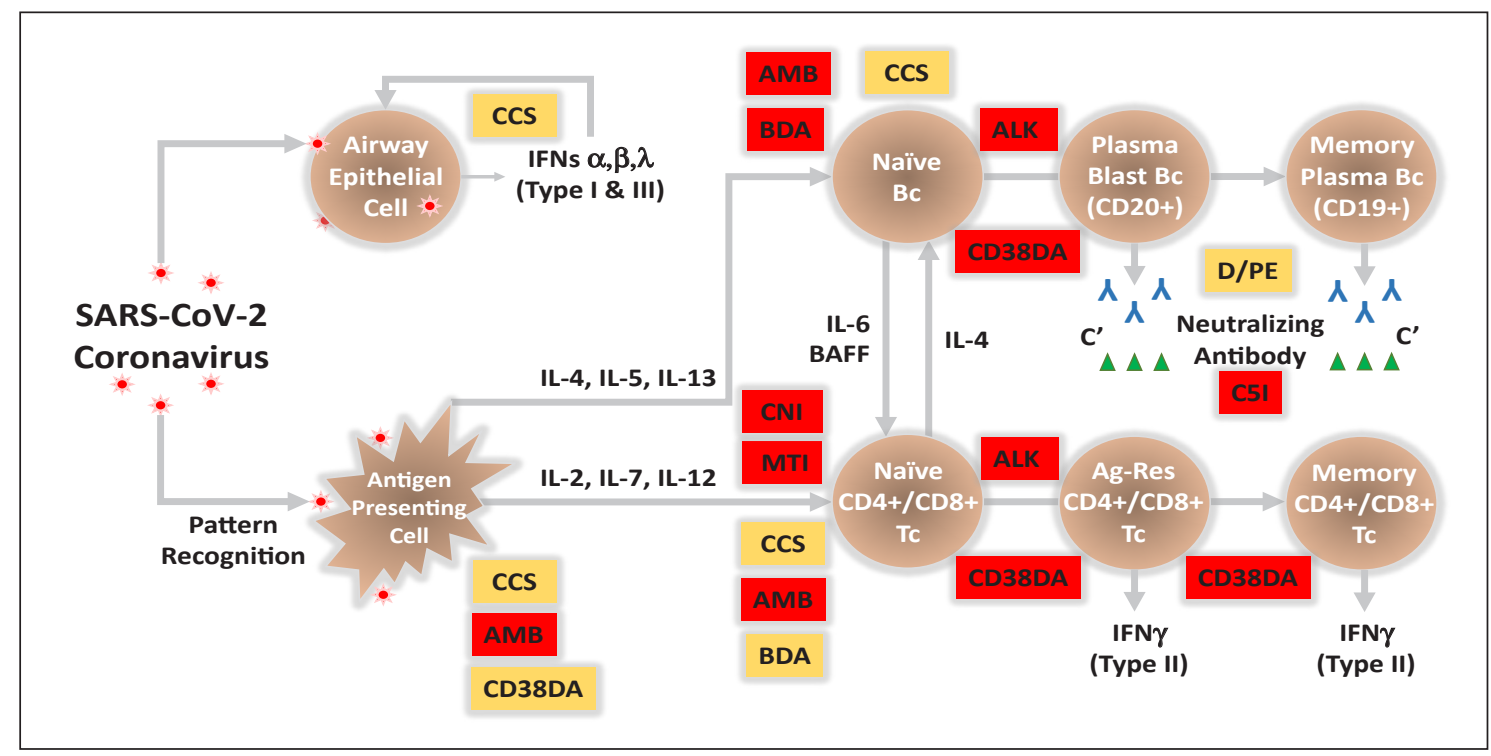

Fig. 1. Potential impact of immunosuppressive therapy on immune responses to SARS-CoV-2 vaccines [5]. Agres, antigen restricted; ALK, alkylating agents; $\mathrm{AMB}$, antimetabolites; BAFF, Bc-activating factor; BDA, Bc-depleting agents; $C^{\prime}$, complement fixation; C5I, complement C5 inhibitors; CCS, corticosteroids; CD38DA, CD38depleting agents; CNI, calcineurin inhibitors; D/PE, dialysis and/or plasma exchange; IFN, interferon; IL, interleukin; MTI, mTOR inhibitors. Therapeutic color scheme: yellow, immune modulation; red, immunosuppression; SARS-CoV-2, severe acute respiratory syndrome coronavirus 2 .

siderable health risks. GD often reflect underlying immune mechanisms, and those that are not primarily immune-mediated may indirectly induce inflammatory change downstream in the tubulointerstitial compartment [2]. Separately and/or together, these ongoing immune and inflammatory processes result in structural injury and fibrotic responses that culminate in progressive renal dysfunction. In treatment-refractory conditions, GD culminates in end-stage renal disease (ESRD). In the USA, GD are the third most common cause of end-stage renal disease [3]. Thus, there is a strong rationale to optimize therapeutic benefit in the treatment of GD.

While specific etiologies of GD are often poorly understood and frequently diagnosed as idiopathic, considerable evidence supports direct and indirect mechanisms of immune dysfunction. For many such diseases, immunosuppression is a mainstay therapeutic strategy, either transiently or permanently. In some cases, immunosuppressive therapies (ISTs) also act directly on podocyte targets. Yet, ISTs introduce explicit risks of infection over and above those already present due to the underlying mechanisms of GD itself. For example, generalized immune dysfunction is a recognized syndrome associated with reduced renal function and uremia [4]. Therefore, reducing risks of preventable infections through vaccination is a highly meritorious clinical strategy. However, ISTs may also attenuate vaccine response and efficacy. The following discussion considers the impact of ISTs on vaccine efficacy in GD, with a focus on COVID-19.

\section{Mechanisms of Vaccine-Induced Immunity against SARS-CoV-2}

Multiple integrated steps are involved in the process of immune response to target antigens in vaccine-induced immunity to the severe acute respiratory syndrome coronavirus 2 (SARS-CoV-2), the etiologic agent of COVID-19 (Fig. 1). Depending on the type of vaccine, these responses may afford relatively rapid nonspecific innate immune protection via interferons (IFNs), followed by adaptive immunity for enhanced specificity and longterm memory. A summary of current vaccines targeting SARS-CoV-2 used internationally is provided in Table 1. The essential steps in vaccine efficacy are reviewed below [5], based on classical vaccines and SARS-CoV-2 vaccine data to date. 


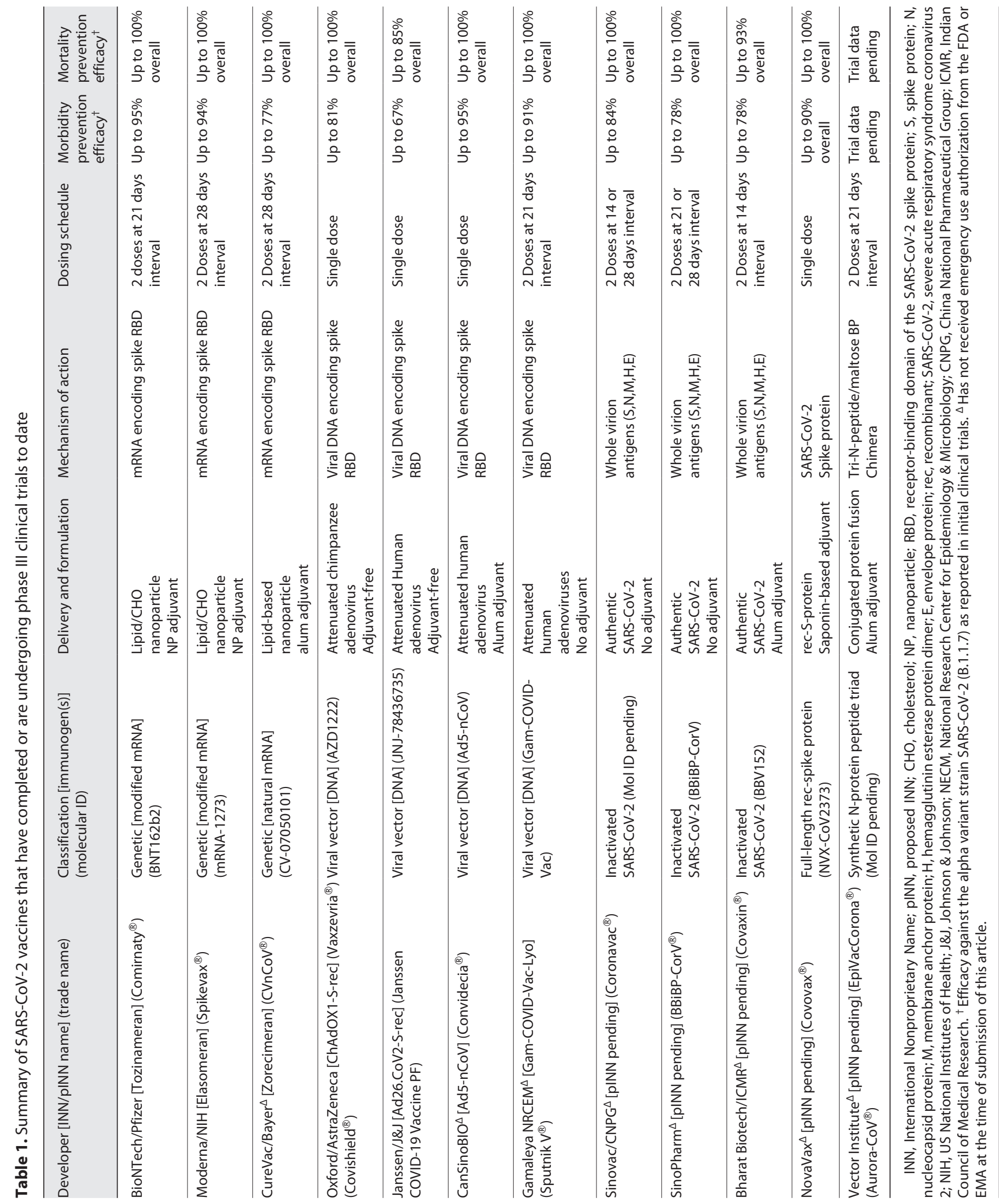




\section{Pattern Recognition}

Signals heralding the threat of infection are termed pathogen-associated molecular patterns (PAMPs). In general, such signals include viral nucleic acids, bacterial peptidoglycan or lipopolysaccharide, and fungal glucans. In balance, signals of host tissue injury due to infection are termed damage-associated molecular patterns (DAMPs). These signals include nuclear elements such as host DNA or histones, mitochondrial constituents such as mitochondrial DNA or formylated peptides, or cytoplasmic warning indicators such as $\mathrm{S} 100$ family proteins, cyclophilin A, or heat-shock proteins. PAMPs and DAMPs are molecular constituents generated in the context of infection that stimulate cognate receptors for subsequent immune response. Among the earliest immune responses to microbial challenge or vaccine exposure are those that occur via constitutive pattern recognition receptors (PRRs) that respond to PAMPs or DAMPs. There are 3 overarching types of PRRs predominant in vaccine response [6]: (1) membrane-bound PRRs, including Tolllike receptors (TLRs) and C-type lectin receptors. TLRs, which now include 10 variants (TLR1 through TLR10) in humans, detect component hallmarks of pathogens, including triacylated lipoprotein (TLR1/2), diacylated lipoprotein (TLR2/6), liposaccharide (TLR4), and bacterial flagellin (TLR5). Notably, TLR10 appears to be a regulatory TLR, modulating responses of the other TLRs. Ctype lectin receptors include the dendritic cell-/macrophage-specific intercellular adhesion molecule and langerin. Dendritic cell-/macrophage-specific intercellular adhesion molecule binds glycans predominantly found on viral, bacterial, and fungal pathogens, while langerin binds mannose-containing ligands unique to or predominant on pathogens and facilitates antigen processing by epidermal Langerhan cells; and (2) endosomal PRRs, including those recognizing double-stranded viral RNA (TLR3), single-stranded viral RNA (TLR7/8), and CpGenriched DNA (TLR9); and (3) cytoplasmic PRRs, such as nucleotide-binding oligomerization domain-like receptors and retinoic acid-inducible gene-1-like receptors. In contrast to their membrane-bound counterparts, nucleotide-binding oligomerization domain-like receptors detect bacterial peptidoglycans, while retinoic acid-inducible gene-1-like receptors are critical for the detection of single- or double-stranded viral RNA that enter the host cell cytoplasm.

Of the COVID-19 vaccine platforms, 3 classes are most likely to stimulate PRRs: the mRNA vaccines and vaccines using inactivated or surrogate viruses for delivery of SARS-CoV-2 DNA [7]. Those containing mRNA simulate viral ss(+)RNA, which ostensibly then directly engages TLR7 or TLR8, and if duplexed activates TLR3. Likewise, inactivated SARS-CoV-2 vaccines that contain the authentic virus in a chemically or otherwise inactivated form are in theory capable of activating TLR7 or TLR8. Vaccines containing viral DNA (viral vector such as adenovirus) have the potential to directly engage TLR9 or, upon transcription to mRNA, may activate TLR3, TLR7, or TLR8. In contrast, recombinant protein vaccines are unlikely to activate TLRs; thus, immune responses to such vaccines may not include rapid protective efficacy by way of innate immunity.

\section{Innate Immune Response}

In response to cognate ligands, PRRs induce 4 thematic classes of innate immune response molecules [8]: (1) IFNs of the type I (IFN- $\alpha$; IFN- $\beta$ ) and type III (IFN- $\lambda$ ) groups; these molecules protect uninfected host cells against challenge from proximate infected cells by inhibiting host cell protein synthesis, inducing nucleases that degrade viral RNA or DNA, and enhancing presentation of viral antigens; (2) eicosanoids such as prostaglandins and leukotrienes; these molecules modulate vascular tone, govern airway status, and regulate platelet function; (3) proinflammatory cytokines such as tumor necrosis factor- $\alpha$ and interleukin-1 $\beta$ (IL- $1 \beta$ ); these cytokines induce fever, promote inflammasome assembly for amplification of cytokine signaling, and mediate programmed cell death of infected host cells; and (4) acute-phase reactants, which include serum amyloid protein A, mannanbinding lectin, C-reactive protein, factor VIII, and other molecules. These immediate response molecules opsonize pathogens for more efficient phagocytosis, facilitate complement-dependent functions and neutrophil navigation, and enhance platelet activation and clot formation to trap pathogens before they access the bloodstream. These classes of immune molecules are induced rapidly in response to microbial threats and considered molecular hallmarks of the innate immune system.

\section{Antigen Presentation}

Detection, processing, and presentation are key first steps determining whether the immune system ignores or actively responds to an antigen. These steps are performed largely by sentinel immune cells, most predominantly DCs. There are distinct forms of DCs, including myeloid DCs and plasmacytoid DCs, either of which can be tissue resident or circulating. Innate lymphoid cells, macrophages (Mf), and other cells also serve as professional antigen-presenting cells (APCs). Myeloid DCs are 
the predominant APCs that display antigenic epitopes for consideration by $\mathrm{T}$ lymphocytes ( $\mathrm{T}$ cells or Tc). Microbial or other foreign antigens are presented in the context of major histocompatibility class II (MHCII), while host self-antigens are generally presented to $\mathrm{Tc}$ in the context of MHC class I (MHCI). B lymphocytes (B cells or Bc) can also be presented epitopes by DC, Mf, or other immune cells. It is increasingly evident that $\mathrm{Bc}$ can also present foreign antigens to $\mathrm{Tc}$, and condition antigen presentation with cytokines such as IL-6. Most host cells present self-antigen epitopes to Tc, which not only enables tolerance but is an ongoing mechanism for immune surveillance of tissue neoplasia or transformation to cancer. Importantly, follicular helper $\mathrm{T}$-cell $\left(\mathrm{T}_{\mathrm{FH}}\right)$ interactions are critical for $\mathrm{Bc}$ germinal center formation and differentiation through somatic hypermutation and affinity maturation. Particularly key in this respect are Bcl-6-expressing $\mathrm{T}_{\mathrm{FH}}$ and germinal center B cells. Defects in this Tc-Bc interplay may diminish protective and durable humoral immunity, in turn enabling or worsening outcomes of COVID-19 $[9,10]$. Likewise, other defects in antigen presentation have recently been linked to severe outcomes in COVID-19 [11].

\section{T-Cell Polarization}

A critical step in adaptive immune response to a given antigen or epitope thereof is Tc polarization. Polarization is the bias of a Tc to promote a specific paradigm of immune response to a cognate antigen in context of cytokine signaling. Tc polarization is intended to customize immune responses best suited to protect against specific microbial threats. General themes of Tc polarization are considered here for comparative purposes [12]. For example, if a Dc presents an antigen in MHCII context and conditions the Tc with IL-12, the naïve Tc will polarize to a Th1 paradigm and secrete (type II) gamma interferon $($ IFN- $\gamma)$. Th1 polarization induces cell-mediated immune mechanisms protecting against intracellular pathogens, including viruses and intracellular bacteria. Effector cells in the Th1 paradigm include Mf, natural killer cells, and cytotoxic $\mathrm{Tc}(\mathrm{CD} 8+)$. By comparison, if a Dc presents antigen in MHCII context but conditions the Tc with IL-6 and transforming growth factor- $\beta$ (TGF- $\beta$ ), the naïve Tc will polarize to a Th17 paradigm and secrete interleukins IL-17A and F (IL-17A/F). Such Th17 polarization induces cell-mediated immunity targeting extracellular pathogens including bacteria and fungi. Neutrophils are the predominant effector cells in the Th 17 paradigm. In contrast, presentation of an antigen in MHCII context but conditioned by IL- 4 polarizes the naïve Tc to a Th2 re-

Immunosuppression and SARS-CoV-2

Vaccines in Glomerular Diseases sponse paradigm. Here, Th2-polarized Tc elaborate IL-5 and IL-13 and prompt Bc activation and class switching for specific antibody production. Importantly, in parallel to Tc responses that promote immune response and inflammation, regulatory Tc (Treg) modulate immune response to antigens, including those in vaccines. Three distinct subsets of Treg have been established, including those expressing high levels of IL-10 (Tr1), TGF-b (Th3), or forkhead box P3 (FoxP3+). Neither the Tr1 nor Th3 Treg classes are known to express FoxP3. Hence, as proinflammatory Tc (e.g., Th1, Th17) are elicited by vaccines, so are Tregs that modulate immune responses to prevent hyperinflammation, cytokine storm, autoimmune, or other adverse responses. Here, balance is imperative, as excessive activation of IL-10-producing Tc is a characteristic of severe COVID-19 [13].

\section{B-Cell Activation}

Upon ligation by antigen and stimulation with $\mathrm{Bc}$-activating factor, $\mathrm{B}$-cell receptors activate Bruton tyrosine kinase to convert the naïve $\mathrm{B}$ cell to an antigen-restricted plasmablast. This transformation includes reassortment of $\mathrm{Bc}$ receptor genes, resulting in isotype or class switching from default $\operatorname{IgM}$ ( $\mu$ heavy chain) to IgG, IgA, IgE, or $\mathrm{IgD}$. Bc activation requires cognate secondary signals, including MHCII complex antigen co-recognition by TcR and appropriate Tc CD40L and CD28 interactions with respective $\mathrm{Bc} C \mathrm{CD} 40$ and $\mathrm{CD} 80 / 86$ molecular partners. Thus, antibody class switching relies on CD4+ Tc activation and cytokine conditioning [14]. It follows that the emergence of IgG, IgA, IgE, or IgD following vaccination represents a biomarker for CD4+ Tc activation. Reciprocally, recent clinical and laboratory evidence has established that Bc play crucial roles in antigen-presenting and cytokine-conditioning that help shape adaptive Tc responses [15]. In these ways, $\mathrm{Bc}$ and their antibody responses are intertwined with Tc regulation, emphasizing the complex interaction of events governing cell-mediated and humoral response to vaccines. Analogous to Tregs, regulatory Bc (Bregs) that express IL-10 (also called B10 $\mathrm{BC}$ ) are induced in response to activation. Such Bregs attenuate any potential off-target or profusive immune responses to antigens that may result in adverse events.

\section{Antibody Production}

The conventional signal of immune response to vaccination is a rise in specific antibody titer to cognate antigens [5]. Rapid induction of specific IgM isotype, followed by the emergence of IgG, IgA, and other isotypes over ensuing days to weeks, is a hallmark of antibody class 
switching [16]. Subclass diversification is another mechanism by which polyclonal antibody responses facilitate optimal immune protection. In protection against viral pathogens such as SARS-CoV-2, IgG subclasses IgG2 and IgG4 are usually best suited for neutralization and inhibition of binding to host cell receptors [17]. Neutralizing antibodies may also clear soluble exotoxins, as is the mode of action of many vaccines (e.g., diphtheria toxin and pertussigen). In contrast, IgG1 and IgG3 bias toward promotion of constant-fragment receptor-mediated opsonization, phagocytosis, and ensuing intracellular killing of pathogens or infected host cells by cytotoxic Tc. Specific IgG1 or IgG3 dimers or IgM monomers can aid in selectively targeting microbicidal activity by classical complement fixation and promote immune cell recruitment to sites of infection via C3a and C5a chemonavigation. Importantly, beyond antigen diversity, human antibody repertoires also undergo experiential improvement in target specificity and affinity over time via a process termed affinity maturation [18]. Here, somatic hypermutation in the complementarity-determining regions of immunoglobulin genes arises in germinal Bc with ongoing antigen stimulation and paracrine signals from follicular helper $\mathrm{Tc}\left(\mathrm{T}_{\mathrm{FH}}\right)$. In this way, antibodies gain greater affinity and immune activity in proportion to experience of exposure to given antigens. The generation of a diverse polyclonal antibody response and affinity maturation that generates progressively optimized specific antibody to critical antigens contribute to protective immunity against SARS$\mathrm{CoV}-2$ variants. Vaccines that induce such responses likely afford that immune system a considerable advantage in these ways.

\section{SARS-CoV-2 Vaccines in Context of Immunosuppression Therapy}

The etiologies of GD commonly involve profusive, offtargeted, and/or host tissue-directed (auto) immune responses. It follows that therapeutics for GD often employ mechanisms of action that attenuate host immune responses. Thus, therapies that suppress immune responses are of special relevance regarding the strength, specificity, or durability of vaccine responses targeting SARS-CoV-2 and protection in GD patients. At the present time, very limited data have been published regarding impacts of IST on these vaccines or their efficacy. Nonetheless, logical insights can be considered based on historical examples, natural immunocompromising conditions, clinical trial findings, and emerging information. Important in this regard are the evolving guidelines provided by authoritative bodies including the US Centers for Disease Control \& Prevention (CDC) Advisory Committee on Immunization Practices [19], the Infectious Diseases Society of America [20], the American Society of Nephrology [21], the American College of Rheumatology [22], the British Society for Immunology [23], and the World Health Organization [24]. Mindful that information is evolving rapidly, the summary below addresses the potential impact of therapeutics commonly used in GD with respect to hypothesized impacts on SARS-CoV-2 vaccine timing or response (Table 2).

\section{Dialysis}

Patients experiencing GD or a related chronic or endstage kidney disorder requiring dialysis often exhibit immunosuppression or attenuated responses to immunization independent of therapeutic regimens [25]. While the specific mechanisms are unclear, potential factors include immunosuppression in relation to chronic uremia, as well as dysfunctions of APC and Tc imposed by dialysis [26]. However, it is apparent that responses to classical vaccines can be blunted in patients receiving dialysis $[27$, 28]. For example, as compared to healthy persons, patients on dialysis had reduced and delayed humoral responses to the BNT162b2 vaccine [29]. In another wellcharacterized cohort of dialysis patients vaccinated with SARS-CoV-2 vaccines that received US FDA emergency use authorization, $9 \%, 35 \%$, and $77 \%$ had detectable antibody responses early postvaccination, and after partial or full vaccination, respectively [30]. Overall results from this study demonstrated that $>20 \%$ dialysis patients demonstrated an attenuated immune response after receiving SARS-CoV-2 vaccination. Consistent with this finding, and increased risks of severe COVID-19 outcomes, dialysis patients have been recommended for prioritization in being vaccinated against SARS-CoV-2 [31].

\section{Plasma Exchange}

There is limited information published to date regarding plasma exchange in the context of COVID-19 vaccination. It is established that this procedure significantly depletes antibody $[32,33]$. For example, plasma exchange (replaced with albumin) may reduce immunoglobulin levels by as much as 95\% [34] and would be expected to do the same for neutralizing or protective antibodies induced by vaccines targeting SARS-CoV-2. Plasma exchange followed by supplemental IVIg therapy has been used safely and effectively to treat immune thrombocytopenia post-SARS-CoV-2 vaccination [35]. The concept of 


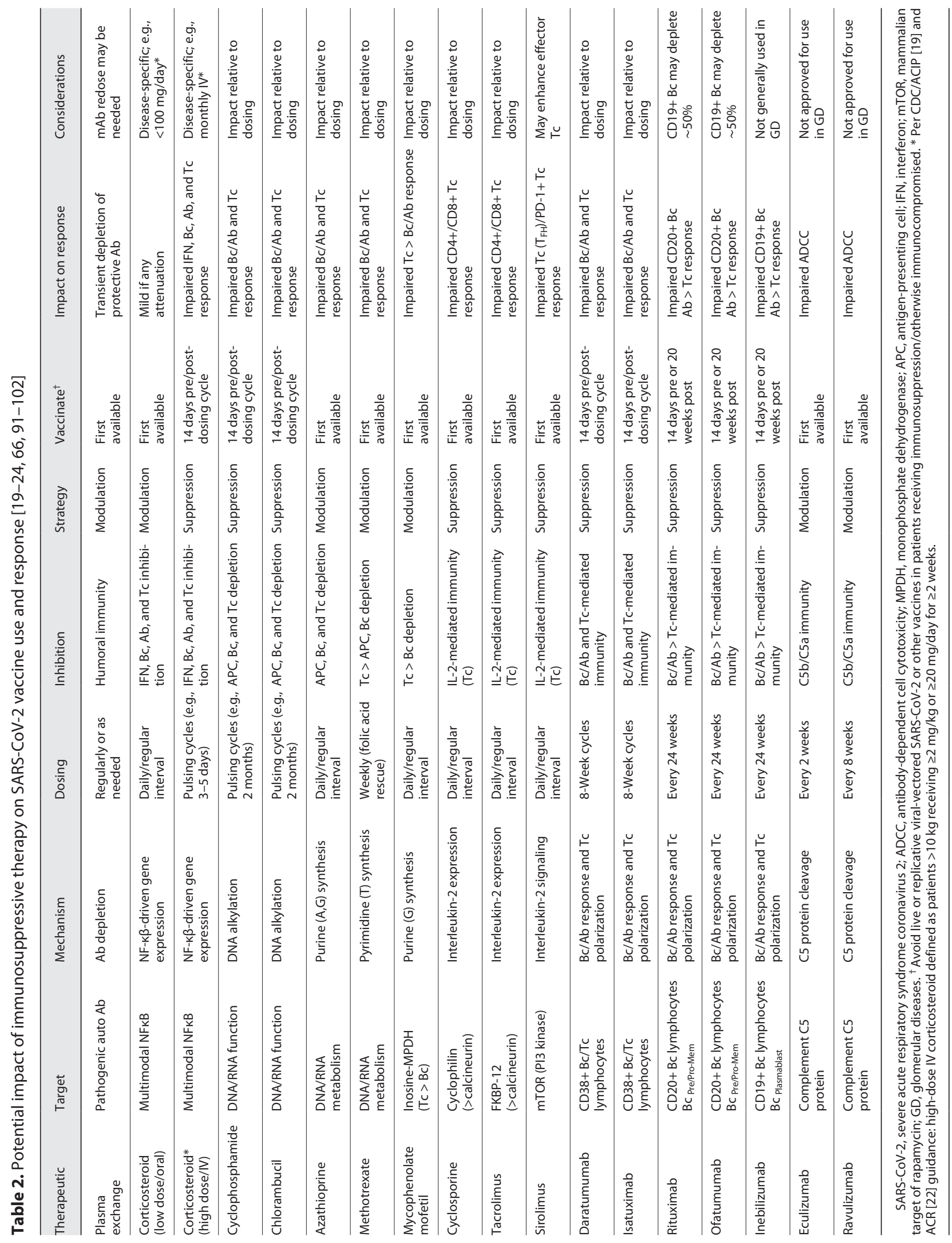


addition of therapeutic monoclonal antibody directed against the SARS-CoV-2 virus or variants to cryosupernatant has been proposed as a means to compensate for removal of protective antibody [36]. Emerging consensus guidelines advise that patients requiring therapeutic plasma exchange continue to receive such treatments where benefits outweigh potential risks [19-24].

\section{Corticosteroids}

Use of corticosteroids (or glucocorticoids) is relatively common in the treatment of chronic kidney diseases, including GD. These agents exert immunosuppressive and anti-inflammatory effects via 2 distinct mechanisms, namely, genomic and nongenomic pathways. Genomic mechanisms involve modulation of NF- $\kappa \beta$ transcription factors responsible for the expression of key inflammatory proteins [37]. Nongenomic mechanisms typically act via glucocorticoid receptors on cells, including podocytes, yielding suppression of proinflammatory signals or functions. Thus, corticosteroids act by inducing immunemodulating pathways (transactivation) and suppressing proinflammatory pathways (transrepression) [38]. Corticosteroids rapidly and significantly attenuate inflammation, beginning with modulation of acute-phase reactants [39]. The most common types of corticosteroids used in GD are short-acting (e.g., prednisone and methylprednisolone; $t 1 / 2 \sim 60-200 \mathrm{~min}$ ) or long-acting (e.g., dexamethasone; $t 1 / 2 \sim 48 \mathrm{~h}$ ) [38]. Interestingly, systemic therapy with prednisone or methylprednisolone may attenuate type III IFN, thereby negating its immunemodulatory effects [40]. In contrast, dexamethasone appears to spare type III IFN responses and attendant immune-modulatory effects, consistent with its efficacy in clinical trials of COVID-19. Subsequent modulation of myeloid and lymphoid cells ensue, resulting in attenuation of $\mathrm{Tc}$ and $\mathrm{Bc}$ functions, as well as neutrophil and other cell-mediated immune effectors. A limited number of studies ranging back to 1974 have examined the impact of systemic corticosteroid therapy on response to vaccination [41]. Steroid effects include lymphopenia, Tc apoptosis, and inhibition of Bc activation and antibody generation in primary or secondary lymphoid organs as well as periphery [42].

The US Centers for Disease Control \& Prevention Advisory Committee on Immunization Practices and Infectious Diseases Society of America (IDSA) consider the threshold of high-dose systemic prednisone-equivalent corticosteroid therapy as that used in patients of $>10 \mathrm{~kg}$ receiving $\geq 2 \mathrm{mg} / \mathrm{kg}$ or $\geq 20 \mathrm{mg} /$ day for $\geq 2$ weeks [19]. Such patients were largely excluded from enrollment in
COVID-19 vaccine clinical trials. By comparison, individuals on dose regimens below this threshold or intermittent administration of oral corticosteroids were not explicitly excluded from these clinical trials. Thus, experience in COVID-19 vaccine response in the setting of lowdose steroid treatment has been gained from clinical trials, as well as from a considerable proportion of the population receiving vaccines since [42]. Overall, results from this experience suggest that immune response to SARS$\mathrm{CoV}-2$ vaccines in patients receiving systemic corticosteroid therapy is sufficient for partial if not greater protective immunity. This view is supported by multiple historical studies of pneumococcal, influenza, and hepatitis $B$ vaccines in patients receiving systemic low- to moderate-dose corticosteroid therapy [43]. Moreover, there appear to be no significant safety risks in using the authorized COVID-19 vaccines in patients receiving corticosteroid therapy. Thus, the American College of Rheumatology guidance recommends no modification in dose regimen or timing of COVID-19 vaccinations in patients receiving $<20 \mathrm{mg} /$ day corticosteroids systemically [22]. For patients receiving high-dose corticosteroid therapy $(\geq 20 \mathrm{mg} /$ day), although no modification of COVID-19 vaccine dosing is recommended, the ACR and other guidance recognize the potential for reduced immune response and protective immunity to vaccination. Thus, alternative strategies are being considered but are not yet recommended, including increased vaccine dosage, additional booster doses, or use of enhancing adjuvants in patients who are strongly immunosuppressed. When possible in patients who have well-controlled disease and without compromising clinical care, high-dose corticosteroid therapy may be titered to a lower dose regimen for 10-14 days before SARS-CoV-2 vaccination. Of special emphasis, systemic high-dose corticosteroid therapy is contraindicated for individuals receiving vaccines that are live or have replicative potential. However, vaccines currently authorized or approved to prevent COVID-19 to date do not use live or replicating attenuated viral platforms, and the adenoviral vectors used in some of these vaccines pose no risk of reversion to a virulent SARS-CoV-2 pathogen.

\section{Alkylating Agents}

As their class name implies, alkylating agents covalently link alkyl functional groups to the 7-nitrogen position of the purine ring in guanine bases of DNA. This mechanism results in multiple inhibitory consequences on DNA function, including inhibiting formation of duplex helices, discontinuous replication, strand fragmentation, and 
cross-linkage of DNA to RNA as hybrid nucleic acid complexes. These effects lead to loss of DNA expression, cell cycle arrest, inhibition of replication, and, ultimately, death often via apoptosis. The rationale for use of these agents in the treatment of GD is inhibition of immune cell development and function resulting in strong immunosuppression [44]. Two commonly used alkylating agents in GD are cyclophosphamide (CYP) and chlorambucil. Given their suppression of myeloid as well as lymphoid progenitors and effectors of immune function, these agents have significant inhibitory consequences on traditional vaccines and are likely to have similar attenuation of COVID-19 vaccine response, efficacy, and durability. Results from animal models of SARS-CoV-2 infection offer important insights into protective immune responses likely to be impaired by alkylating agents such as CYP. For example, CYP-treated hamsters have more severe COVID-19-like disease than untreated controls, including greater viral load, duration of symptoms, and mortality [45]. Thus, immune constituents necessary for protective responses to natural SARS-CoV-2 infection - and by extension COVID-19 vaccination - are inhibited by CYP. Beyond typically significant myelopenia and lymphopenia, alkylating agents including CYP and chlorambucil attenuate Dc recognition, processing, and presentation of antigens to $\mathrm{Tc}$ and $\mathrm{Bc}$ [46]. In turn, such inhibition impairs CD4+ Tc polarization and downstream molecular and cellular antiviral efficacy. In addition, alkylating agents promote type I IFN expression, an effect that may counter suppress beneficial responses of type II (IFN- $\gamma$ ) or type III (IFN- $\lambda$ ) IFNs [40]. Based on these mechanisms, alkylating agents are likely to significantly attenuate immune responses to the authorized COVID-19 vaccines. However, the ACR guidance recommends no modification in dose regimen or timing of authorized COVID-19 vaccinations in patients receiving CYP or other alkylating agent therapy [22]. This view is supported by 2 basic concepts: (1) even if attenuated, the risks of COVID-19 argue in favor of any enhanced immune protection afforded by vaccination; and (2) low-dose or intermittent pulsing of CYP appears to preferentially target Tregs [47]. If so, it is at least conceivable that semiselective repression of Tregs in CYP therapy may favor efficacious responses to COVID-19 vaccines, particularly regarding durability of memory.

\section{Antimetabolites}

A mainstay of GD therapy that is comparatively less immunosuppressive than alkylating agents is the group of therapeutic antimetabolites, including azathioprine

Immunosuppression and SARS-CoV-2

Vaccines in Glomerular Diseases
(AZA), methotrexate (MTX), and mycophenolate mofetil (MMF). Although these agents have distinct mechanisms of action, they converge on nucleic acid metabolism essential to the generation and function of immune and other host cells. Azathioprine is a selective inhibitor of purine synthesis due to its conversion to 6-mercaptopurine and subsequently 6-thioguanine nucleotide analogs. In turn, these molecules competitively integrate into DNA in place of guanine, resulting in arrested replication and apoptosis of cells having a high rate of replication. In this respect, myeloid and lymphoid cells of the immune system are semiselectively targeted for inhibition by AZA. Alternatively, MTX impairs the synthesis of dihydrofolate and tetrahydrofolate by competitive inhibition of dihydrofolate reductase. The consequences of this inhibition are many, as dihydrofolate and tetrahydrofolate are critical for nucleic acid synthesis and the generation of specific amino acids emanating from thymine-activated substrates. The suppression of nucleotide and protein biosynthesis by MTX is semiselective for cells undergoing rapid replication or intensive functions, including those of the immune system. In contrast, MMF is a preferential inhibitor of inosine monophosphate dehydrogenase. This enzyme is a committed step in guanine biosynthesis and is enriched in lymphocytes. For these reasons, MMF is a semiselective inhibitor of lymphocyte proliferation, preferentially affecting Tc [48].

Considerable data have been published examining the impacts of AZA, MTX, or MMF on traditional vaccines which shed light on their anticipated effects on COVID-19 vaccines. In adult patients with chronic kidney disease leading to transplant, AZA did not negatively impact influenza vaccine safety or protective antibody response as compared to matched healthy controls [49]. By comparison, MMF attenuated antibody response to influenza A/H1N1 in this cohort. Importantly, MMF treatment in patients with rheumatic disease also impaired antibody responses to a single dose of the BNT162b2 (BioNTech/Pfizer) COVID-19 vaccine [50]. However, in this cohort of patients with native kidneys, the use of MTX did not attenuate the humoral response to influenza vaccination. In a separate study, MTX was found to significantly impair antibody response to vaccines targeting influenza A or B, while tocilizumab (anti-IL-6 receptor) did not [51, 52]. However, antibody response was considered to be adequate for protection, and no serious adverse events or disease relapses were seen postvaccination in the study cohort of 194 RA patients of whom $21 \%$ used daily lowdose steroids. Likewise, MTX impaired antibody responses to seasonal influenza and pneumococcal vaccination in 
rheumatoid arthritis patients $[53,54]$. When used in solid organ transplant cases, MMF or AZA therapy correlated with significantly lower antibody response to either of the mRNA vaccines targeting SARS-CoV-2 [55]. Based on these and other emerging data, antimetabolites (e.g., AZA, MMF, and MTX) are likely to impair humoral responses to COVID-19 vaccination modestly, moderately, or significantly relative to dosing, underlying morbidity, adjunctive interventions (e.g., dialysis), and other factors. Whether these agents impact IFN and/or Tc responses to COVID-19 vaccines is not yet known.

\section{Calcineurin and mTOR Inhibitors}

Calcineurin is a serine/threonine phosphatase primarily responsible for activating the transcription factor, nuclear factor activator-T cells; the nuclear factor activator$\mathrm{T}$ cell is critical for CD4+ Tc activation and IL-2 generation. In turn, IL-2 stimulates amplification and function in $\mathrm{Tc}, \mathrm{NKc}$, and $\mathrm{Bc}$ populations in host defense. To induce IL-2 generation, calcineurin is enabled through binding by 1 of 2 proline isomerases: cyclophilin or immunophilin (FKBP-12). Calcineurin inhibitors competitively bind to cyclophilin (cyclosporine) or immunophilin (tacrolimus), thereby preventing cyclophilin or immunophilin interactions with and activation of calcineurin. Hence, calcineurin inhibitors are indirect inhibitors of IL-2 production by $\mathrm{Tc}$, resulting in suppression of Tc-mediated immunity. By comparison, inhibitors of the mammalian target of rapamycin (mTOR) impede the function of phosphatidylinositol-3 kinases that regulate the regulatory proteins $\mathrm{mTORC} 1$ and $\mathrm{mTORC} 2$. Thus, there are 2 principal classes of IL-2 inhibitors: (1) calcineurin inhibitor polyketides - e.g., cyclosporin(e), voclosporin(e), and tacrolimus; these agents bind to cyclophilin or immunophilin FKBP-12 to inhibit calcineurin-mediated IL-2 generation; and (2) mTOR inhibitor macrolide lactones - e.g., sirolimus, everolimus, or pimecrolimus; these agents bind to mTOR and thus inhibit downstream signaling critical for IL-2 generation. Of note, these classes of compounds derive from microorganisms (e.g., cyclosporin(e) from the fungus Tolypocladium inflatum; tacrolimus from the bacterium Streptomyces tsukubaensis; and sirolimus from the bacterium Streptomyces hygroscopicus) that apparently evolved them to modulate the immune system as a means of virulence.

Inhibition of IL- 2 can impact on vaccine response and protective efficacy. Consistent with their primary mechanism to inhibit Tc response, antibody response to conventional immunizations such as influenza or pneumococcal vaccines is often minimally or modestly affected by the calcineurin or mTOR inhibitors [56, 57]. Moreover, antibody responsivity to SARS-CoV-2 vaccination is likely to be blunted when calcineurin inhibitors are used in combination with antimetabolites such as MMF [50, 55, 58]. Likewise, protective immunity from COVID-19 vaccines may be muted following a first dose of vaccine [59], emphasizing the importance of the second boosting doses of mRNA vaccines. Of potentially greater concern is the impact of calcineurin inhibitors on critical Tc responses to COVID-19 vaccines. Essentially, tacrolimusbased regimens are designed to impair Tc and IL-2-mediated adaptive immunity. However, several lines of evidence in conditions other than GD provide insights to suggest that calcineurin and IL-2 inhibition may only moderately impact vaccine efficacy. First, IL-2 monoclonal therapies such as daclizumab permit normal Tc and $\mathrm{Bc}$ responses to influenza vaccination [60]. Interestingly, the IL-2 inhibitor basiliximab appeared to inhibit generation of memory Bc in kidney transplant patients - but did not impair generation of acute antibody levels - in response to trivalent influenza vaccination [61]. Second, $\mathrm{CD} 8+\mathrm{Tc}$ are increasingly being recognized as key biomarkers of protective immunity against COVID-19 [62]. Importantly, recent evidence suggests that tacrolimus specifically inhibits $\mathrm{CD} 4+\mathrm{T}_{\mathrm{FH}}$ cells, relatively sparing other Tc subsets [63]. If so, then in concept tacrolimus and related calcineurin inhibitors may have only modest to moderate impact on protective Tc responses to $\mathrm{CO}$ VID-19 vaccines. It should be noted that cocktail regimens involving calcineurin inhibitors are likely to have greater impairment of vaccine responses than these agents alone. For example, in kidney transplant patients on combination therapy involving tacrolimus, cyclosporine, or MMF, CD4+ and CD8+ Tc responses in particular were nearly undetectable following BNT162b2 vaccination targeted against SARS-CoV-2 [58]. Nonetheless, the benefits of COVID-19 vaccination are believed to greatly outweigh risks of severe COVID-19 or muted immune responses to vaccination. Interestingly, data from vaccine studies in rhesus macaques indicate that mTOR inhibitors such as sirolimus may enhance viral-specific $\mathrm{CD} 8+\mathrm{Tc}$ responses [64]. In humans, everolimus enhanced immune response to influenza vaccination by nearly $20 \%$ in specific antibody titer, particularly in elderly individuals [65]. Mechanistically, data suggested that everolimus semiselectively inhibits CD4+ and CD8+ Tc expressing high levels of the programmed cell death-1 receptor, which is more highly expressed with aging. Whether such effects occur with SARS-CoV-2 is not yet known. Guidelines recommend that vaccines to prevent 
COVID-19 be prioritized or provided with no delay to patients who are on calcineurin or MTOR inhibitor therapy, with no change in dosing or schedule of treatment $[24,66]$.

\section{CD38+ Cell-Depleting Agents}

The cell differentiation marker CD38 is a $45-\mathrm{kDa}$ glycoprotein ectoenzyme expressed on multiple immune cell lineages, including plasma $\mathrm{Bc}$ in addition to $\mathrm{CD} 4+$ and CD8+ Tc [67]. CD38 is also expressed on NKc, although its role in this cell lineage remains unclear [68]. Functionally, CD38 is a cyclic adenosine diphosphate ribose cyclase and hydrolase involved in the signal transduction and activation of $\mathrm{Bc}$ and $\mathrm{Tc}$. Inhibition of its enzymatic functions results in dysregulated ribose metabolism that ultimately leads to cell apoptosis. CD38 expression is highest on naive $\mathrm{Bc}$ and $\mathrm{Tc}$, with considerably lower expression on mature, differentiated cells [69]. Importantly, CD38-mediated activation of Bc occurs via associations with CD19 and CD21; on Tc or NKc, CD38 signaling requires a functional interaction with the $\mathrm{CD} 3$ receptor complex or CD16, respectively. Despite its potential to target multiple immune cells, CD38 cell depletion ostensibly targets $\mathrm{Bc}$ and pathogenic $\mathrm{Ab}$ production in GD. Two anti-CD38 monoclonal antibody therapeutics commonly used in GD are considered here: daratumumab and isatuximab. Felzartamab and mezagitamab are next-generation anti-CD38 monoclonal antibodies reportedly with higher affinity (felzartamab) or enhanced cytolytic activity (mezagitamab) currently in clinical trials for membranous nephropathy and multiple myeloma.

Relatively little information has been published regarding the impact of anti-CD38 therapies on vaccine responses. Polyclonal IgG responses to pneumococcal or Haemophilus influenzae vaccinations were unaffected by daratumumab therapy in patients with multiple myeloma [70]; notably however, polyclonal IgA, IgE, and IgM were diminished. This pattern corresponded with a reduction in class-switched CD38 + B plasma cells in the bone marrow. Interestingly, plasma cells with reduced CD38 expression survived daratumumab and were believed to be responsible for the normal IgG response. Recent insights have shed light on the potential impact of anti-CD38 agents on the immune response to COVID-19 vaccination. Following the first dose of the BNT162b2 vaccine, patients on daratumumab exhibited lower neutralizing antibody titers than controls in preliminary studies in an ongoing clinical trial [71]. If this effect proves to be true in larger studies, it would highlight the relationship between $\mathrm{Bc}$ activation and generation of antibody in re-

Immunosuppression and SARS-CoV-2

Vaccines in Glomerular Diseases sponses to SARS-CoV-2 or other vaccines. Guidelines for the use of anti-CD38 therapy in the setting of vaccination against COVID-19 are to vaccinate prior to initiation of treatment or delay vaccination 90 days following the last treatment cycle [19-24].

\section{CD20+ and CD19+ Cell-Depleting Agents}

Therapeutic targeting of $\mathrm{CD} 20+$ and $\mathrm{CD} 19+\mathrm{Bc}$ is among the most common strategies to treat diseases involving pathogenic antibody. Examples of more recent approaches in this regard include the belimumab (targeting the Bc-activating factor) and Bruton kinase inhibitors such as ibrutinib. However, mainstay $B c$ inhibitors used in treating GD have largely focused on CD20 Bc depletion. Since the advent of rituximab representing this class of agents, many anti-CD20 monoclonal therapies have emerged for treating diseases ranging from hematologic cancers to autoimmune diseases. These CD20-targeting biologics include ocrelizumab, ofatumumab, obinutuzumab, and ublituximab. Biologics targeting CD20 induce both antibody-dependent cell cytotoxicity (ADCC) and complement-dependent cytotoxicity, resulting in the lysis of $\mathrm{Bc}$ expressing this marker. These agents lead to nearly complete ablation of $\mathrm{CD} 20+\mathrm{Bc}$ from the peripheral circulation; significant depletion of such cells typically endures for 6 months post-infusion. In contrast, CD20+ cells appear to persist in tissues after the infusion of anti-CD20 agents such as rituximab, including in lymph nodes [72]. In 2020, inebilizumab became the first FDA-approved therapeutic targeting $\mathrm{Bc} C D 19$; its first indication was the neurological autoimmune disease, neuromyelitis optica [73]. Because CD19 is expressed on terminally differentiated memory Bc plasma cells (i.e., CD19+/CD27+), while CD20 is not, anti-CD19 agents may target a greater span of $\mathrm{Bc}$ involved in autoimmune GD. It should be noted that subsets of Tc also express CD19 and CD20 and are depleted by anti-CD19 and anti-CD20 biologic drugs [74, 75]. Thus, depleting CD8+ Tc interactions with CD19+ or $\mathrm{CD} 20+\mathrm{Bc}$ is now considered to contribute to the salutatory efficacy of Bc-depleting agents targeting these markers in autoimmune or related diseases.

Therapeutics that deplete or inhibit $\mathrm{Bc}$ responses significantly attenuate immune responses to vaccine antigens. As expected based on their primary targeting of $\mathrm{Bc}$, the predominant effect of these agents focuses on impaired humoral immunity. Regarding conventional vaccines, the most recent data come from the VELOCE study of ocrelizumab in patients with multiple sclerosis [76]. As compared to control patients treated with IFN- $\beta$, those on ocrelizumab generated significantly lower antibody ti- 
ters in response to tetanus toxoid or pneumococcal vaccines. Seropositive response (2- to 4-fold titer increase after 8 weeks) to tetanus or pneumococcal immunization was $23.9 \%$ or $71.6 \%$, respectively, in ocrelizumab treatment, while $54.5 \%$ and $100 \%$, respectively, in controls. Similar results were seen in rituximab-treated neuromyelitis optica patients, where antibody responses to H1N1 influenza vaccination were substantially reduced as compared to controls [77]. It should be emphasized that Bc depletion does not entirely eliminate antibody response to conventional vaccines, despite the near absence of circulating $\mathrm{CD} 20+\mathrm{Bc}$ for much of the dosing interval. This observation highlights 2 important concepts relevant to COVID-19 vaccination: (1) CD20+ Bc beyond the peripheral compartment may respond to vaccine antigens; and (2) terminally differentiated CD19+ Bc may account for antibody generation in the absence of $\mathrm{CD} 20+\mathrm{Bc}$ subsets (e.g., $\mathrm{CD} 20^{-} / \mathrm{CD} 19^{+} \mathrm{Bc}$ plasmablasts).

Relative to the above information, limited data have been published regarding Bc-depleting therapy in the context of COVID-19 vaccination. As anticipated from its mechanism of action and effects on conventional immunizations, rituximab significantly impaired antibody response to the first dose of BNT162b2 vaccine [50]. Recognizing the durability of Bc-depleting biologics on target cell repletion is also to be considered in COVID-19 vaccination strategies for such patients. Kinetics of $\mathrm{Bc}$ repletion varies considerably among anti-CD20 agents, with a mean range of $80 \%$ repopulation of baseline $\mathrm{CD} 20 \mathrm{Bc}$ count by 35 weeks postrituximab, 40 weeks post-ofatumumab, and 72 weeks postocrelizumab [78]. Based on these factors, emerging consensus guidelines [19-24] advise that COVID-19 and other immunizations be updated prior to initiation of anti-CD20 or anti-CD19 biologic therapy when practical. If vaccinations are to be given while on therapy, protective immune responses may be maximized toward the end of the dosing cycle (e.g., 4-6 months after prior dose), when Bc and Tc populations have recovered. A related consideration is to delay subsequent $\mathrm{Bc}$-depleting biologic dose by 4 weeks for patients whose disease is well controlled to allow for best COVID-19 vaccine-induced immunity to be imparted. Each of these strategies should be weighed against the relative risks of severe COVID-19 in the absence of vaccination, and a potential for Bc-depleting therapy to prolong viral shedding or increase morbidity and mortality due to SARSCoV-2 infection [79].

\section{Complement Inhibitors}

Beyond their direct pathogenic effects, some autoantibodies in GD are capable of fixing complement to initiate a cascade of inflammation and tissue injury. This process of classical complement fixation $\left(\mathrm{C}^{\prime}\right)$ is known as ADCC. First, recognition of the IgG dyad or IgM pentamer autoantibody constant fragment $(\mathrm{Fc})$ region by complement protein $\mathrm{C} 1 \mathrm{q}$ catalyzes the initiation complex, C1qrs. In turn, this complex activates complement proteins 2 (C2) and 4 (C4) to form a heterocomplex termed C4b2a. This complex cleaves complement protein $\mathrm{C} 3$ into $\mathrm{C} 3 \mathrm{a}$ and $\mathrm{C} 3 \mathrm{~b}$. Next, $\mathrm{C} 3 \mathrm{~b}$ protein complexes to $\mathrm{C} 4 \mathrm{~b} 2 \mathrm{a}$, forming $\mathrm{C} 3 \mathrm{~b} 4 \mathrm{~b} 2 \mathrm{a}$, or complement protein 5 (C5) convertase. Cleavage of $\mathrm{C} 5$ is an important committed step in the $\mathrm{C}^{\prime}$ cascade, as it generates $\mathrm{C} 5 \mathrm{a}$ and $\mathrm{C} 5 \mathrm{a}$ derivative fragments. Fragment $\mathrm{C} 5 \mathrm{~b}$ binds to the target cell and directs ensuing binding of the membrane attack complex, C6-C9. This effector complex perforates the target cell membrane, leading to cell injury, cytokine elaboration, and death. In parallel, C5a protein diffuses from the site of generation as a chemotactic signal for recruitment of immune cells including inflammatory neutrophils. In this way, C5 cleavage results in the direct injury of glomerular tissues via the C6-C9 attack complex and recruitment of a highly proinflammatory immune cell milieu leading to further tissue damage.

With respect to ADCC, $\mathrm{C} 5$ inhibitors are often used to treat GD. Two anti-C5 biologics are most commonly employed for this purpose: eculizumab and ravulizumab. Currently, a small-molecule inhibitor of C5 - avacopan - is pending FDA approval for use in anti-neutrophil cytoplasmic antibody vasculitis [80]. This agent binds to C5a receptor on immune cells, preventing it from binding to its cognate ligand $\mathrm{C} 5 \mathrm{a}$, thereby inhibiting chemoattraction [81]. Inhibitors of other steps in the $\mathrm{C}^{\prime}$ cascade are in clinical trial evaluation. These include narsoplimab - a monoclonal $\mathrm{Ab}$ inhibitor of the mannose-binding lectin serine protease (MASP2) involved in alternative $\mathrm{C}^{\prime}$ pathway activation - in clinical trials for treatment of IgA nephropathy [82].

Whereas complement inhibition can strongly impair $\mathrm{ADCC}$ by preformed Ab, information is limited regarding the impact of complement inhibition on response to vaccine itself. Complement inhibitors have variable effects on protective responses to most conventional vaccines. For example, eculizumab impaired protective serum bactericidal titer response in $~ 50 \%$ of atypical hemolytic uremia syndrome (aHUS) patients following vaccination for serogroup B meningococcal disease [83]. In this cohort, vaccination induced robust and protective vaccine serum bactericidal responses in aHUS in the absence of eculizumab, indicating that uremia per se was not the cause of vaccine attenuation. Similarly, therapy 
with eculizumab appeared to attenuate protective antibody response to the first dose of MenACWY vaccine in aHUS patients [84]. Of the 25 patients studied, 20 had no or incomplete protective response to 1 or more $N$. meningiditis serogroups after vaccination. The second dose vaccination improved responses in 9 of the 20 patients with nonprotective immune responses to the first dose. It should be noted that the role of worse uremia at the time of first vaccine dose in these patients cannot be ruled out as the basis for reduced vaccine efficacy. This concept is supported by the observation that response to MenACWY vaccine in paroxysmal nocturnal hemoglobinuria was significantly better than that observed in aHUS patients [85]. While viral infections have been reported correlating complement inhibitor therapy, these are exceedingly rare [86]. This clinical experience is consistent with ADCC having a relatively lesser role in clearance of viral infected host cells than CD8+ Tc and other cell-mediated mechanisms. Thus, while almost no data are yet available, the impact of complement inhibition on response to SARS-CoV-2 vaccines is expected to be nominal and guidance $[19-24,66]$ accordingly encourages vaccination in most patients.

Guidelines for patients on complement inhibitor therapy typically require vaccine regimens (e.g., MenACWY and serogroup $\mathrm{B}[\mathrm{MenB}]$ meningococcal vaccines) prior to initiation when possible [87]. Additional booster doses may enhance protective efficacy or durability while on complement inhibitor therapy. While almost no data are available presently, this same approach is also advised regarding SARS-CoV-2 vaccination. This reasoning derives from the observations that vaccines appear safe among immunocompromised patients, and even a reduced protective immunity is better than no protective immunity in GD patients who may be at heightened risk of severe outcomes in COVID-19 [88].

\section{Potential Strategies for Optimal Vaccine Response}

The impact of immunosuppression on vaccines designed to prevent COVID-19 awaits more knowledge derived from published clinical studies. Even so, as detailed above, some therapies have already been shown to attenuate immune response of vaccines targeting SARS$\mathrm{CoV}-2$. Bomback et al. [89] recently suggested potential modifications to certain therapeutic regimens, diagnostic or monitoring practices, supportive care, and clinical visits for GD patients during the COVID-19 pandemic. For example, discontinuation of anti-metabolites was pro- posed for patients with suspected or confirmed infection by SARS-CoV-2, or in patients with sustained GD remission for $>12$ months. Recommendations also included routine vaccinations against influenza and pneumococcus but did not address vaccination against SARS-CoV-2. In light of heightened risks of SARS-CoV-2 delta variant (B.1.617.2) exposure and potentially worse COVID-19, guidance from the vast majority of authoritative bodies recommends vaccination of patients on immunosuppression therapy, including GD patients [19-24, 66]. Several authoritative bodies recommend that patients receiving immunosuppressive therapies be prioritized for SARS-CoV-2 vaccination. Even so, specific recommendations for vaccination may vary slightly based upon therapeutic regimens or other clinical management uniquely implemented during the ongoing COVID-19 pandemic.

It should be noted that there have been a small number of case reports of apparent de novo or relapsing GD following SARS-CoV-2 vaccination [90]. Of the 26 cases cited occurring within 3 weeks postvaccination, included were 10 cases each of minimal change disease and immunoglobulin A nephropathy. The authors cautioned that the extremely small number of cases reported relative to hundreds of millions of vaccines dosed could reflect simple coincidence or unmasking of previously undiagnosed disease. Further, while most of these reported cases occurred following the use of $\mathrm{mRNA}$ vaccines, this relationship is likely reflective of the significantly greater number of mRNA vaccines administered. Such case reports represent an infinitesimally small proportion of persons who have safely received vaccination and gained life-saving protective immunity against COVID-19. Thus, the benefits of vaccination greatly outweigh any highly remote risk of de novo GD or relapse, and proceeding with vaccination is strongly recommended by the authors.

Experience regarding the impact of immunosuppression on conventional vaccines may shed light on potential strategies to optimize efficacy of the COVID-19 vaccines. In this respect, current guidelines resonate around consideration of one or more of the following strategies [1924, 66, 89-101]:

- Avoid vaccines containing live or replicative-competent viral vectors in GD patients (or any patients) receiving IST;

- Vaccinate prior to initiation of IST whenever feasible; do not delay therapy if that would increase risk of worsening GD;

- Consider alteration or transient discontinuation of certain immunosuppressive regimens if patients are 
suspected or confirmed to have SARS-CoV-2 infection, or who have achieved long-term remission of their GD or immune-mediated disease (e.g., for $>12$ months prior) [89];

- For therapies resulting in profound Bc or Tc depletion for protracted time, vaccinate prior to initiation of therapy or at logical time windows when immune responses have partially or fully recovered prior to next dose cycle;

- Monitor immune biomarkers of protective immunity to SARS-CoV-2 postvaccination as these become more specifically characterized with additional research;

- Consider additional doses/boosting based on response or durability of prior vaccine doses [92-95]. The US FDA recently provided emergency use authorization for a booster dose of the mRNA vaccine(s) (e.g. BioNTech/Pfizer FDA emergency use authorization for third dose booster as of 9/22/2021) in certain immunocompromised persons, including those on treatment regimens that substantially suppress immune response [96].

- Consider modification of vaccine dose or interval in specific patients define as at-risk due to immunosuppression following local, regional, or national health authority policies [97-100];

- While not yet available or approved, consider emerging options to alter the mode of vaccine administration (e.g., intradermal or intranasal vs. intramuscular) to address intramuscular needle injection hesitancy or potentially enhance contextual immune responses (e.g., IgA in airway epithelium) [101, 102].

- Consider administering SARS-CoV-2 vaccines in combination with traditional immunizations (e.g., influenza) to leverage opportunities to enable protective immunity against other known transmissible diseases afforded by standard vaccines [92].

\section{Acknowledgments}

The author wishes to extend gratitude to participants of clinical trials from which important knowledge is gained to the altruistic benefit of others. This theme is magnified in clinical research performed to better understand, prevent, and treat COVID-19.

\section{Statement of Ethics}

This review did not involve the use of animals or human subjects. It adheres to the standards put forth by the Committee on Publication Ethics (COPE).

\section{Conflict of Interest Statement}

The author has no conflicts of interest to declare.

\section{Funding Sources}

The author was supported in-part by the US National Institutes of Health, National Institute of Allergy and Infectious Diseases (NIAID) Grant No. U01-AI-124319 (to M.R.Y.)

\section{Author Contributions}

The author conceived and drafted the manuscript, and created the tables and figure.

\section{Data Availability Statement}

Data that support the themes of this review are available as referenced. Where practical, references include active links to regularly updated data sources from authoritative bodies to facilitate access of latest information that may have emerged after the submission of this review.

\section{References}

1 Myers OB, Pankratz VS, Norris KC, Vassalotti JA, Unruh ML, Argyropoulos C. Surveillance of CKD epidemiology in the US: a joint analysis of NHANES and KEEP. Sci Rep. 2018;8(1):15900.

2 Chen TK, Knicely DH, Grams ME. Chronic kidney disease diagnosis and management: a review. JAMA. 2019;322:1294-304.

3 Romagnani P, Remuzzi G, Glassock R, Levin A, Jager KJ, Tonelli M, et al. Chronic kidney disease. Nat Rev Dis Primers. 2017;3:17088.

4 Cohen G, Hörl WH. Immune dysfunction in uremia: an update. Toxins. 2012;4(11):96290.
5 Yeaman MR, Hennessey JP Jr. Innovative approaches to improve anti-infective vaccine efficacy. Annu Rev Pharmacol Toxicol. 2017; 57:189-222.

6 Pulendran B, S Arunachalam P, O'Hagan DT. Emerging concepts in the science of vaccine adjuvants. Nat Rev Drug Discov. 2021;20(6): 454-75.

7 Tay MZ, Poh CM, Rénia L, MacAry PA, Ng LFP. The trinity of COVID-19: immunity, inflammation and intervention. Nat Rev Immunol. 2020;20:363-74.
8 Amarante-Mendes GP, Adjemian S, Branco LM, Zanetti LC, Weinlich R, Bortoluci KR. Pattern recognition receptors and the host cell death molecular machinery. Front Immunol. 2018;9:2379.

9 Dan J, Mateus J, Kato Y, Hastie KM, Yu ED, Faliti CE. Immunological memory to SARSCoV-2 assessed for up to 8 months after infection. Science. 2021 Feb;371(6529):eabf4063.

10 Kaneko N, Kuo HH, Boucau J, Farmer JR, Allard-Chamard H, Mahajan VS, et al. The loss of Bcl-6 expressing $\mathrm{T}$ follicular helper cells and the absence of germinal centers in COVID-19. SSRN. 2020;183:3652322-57. 
11 Saichi M, Ladjemi MZ, Korniotis S, Rousseau C, Ait Hamou Z, Massenet-Regad L, et al. Single-cell RNA sequencing of blood antigenpresenting cells in severe COVID-19 reveals multi-process defects in antiviral immunity. Nat Cell Biol. 2021;23(5):538-51.

12 Grifoni A, Weiskopf D, Ramirez SI, Mateus J, Dan JM, Moderbacher CR, et al. Targets of T cell responses to SARS-CoV-2 coronavirus in humans with COVID-19 disease and unexposed individuals. Cell. 2020;181:1489-501. e15.

13 Neumann J, Prezzemolo T, Vanderbeke L, Roca CP, Gerbaux M, Janssens S, et al. Increased IL-10-producing regulatory $\mathrm{T}$ cells are characteristic of server cases of COVID-19. Clin Trans Immunol. 2020 Nov 13; 9(11):e1204.

14 Steinman L, Bar-Or A, Behne JM, Benitez-Ribas D, Chin PS, Clare-Salzler M, et al. Restoring immune tolerance in neuromyelitis optica: part I. Neurol Neuroimm Neuroinflamm. 2016;3(5):e276

15 Barnett LG, Simkins HM, Barnett BE, Korn LL, Johnson AL, Wherry EJ, et al. B cell antigen presentation in the initiation of follicular helper $\mathrm{T}$ cell and germinal center differentiation. J Immunol. 2014;192:3607-17.

16 Di Noia JM. Molecular biology: unequal opportunity during class switching. Nature. 2015;525:44-5.

17 Nielsen SCA, Yang F, Jackson KJL, Hoh RA, Röltgen K, Stevens B, et al. Human B cell clonal expansion and convergent antibody responses to SARS-CoV-2. bioRxiv. 2020;28(4): 516-25.

18 Mishra AK, Mariuzza RA. Insights into the structural basis of antibody affinity maturation from next-generation sequencing. Front Immunol. 2018;9:117.

19 US Centers for Disease Control and Prevention. Advisory Committee on Immunization Practices (ACIP) COVID-19 vaccine recommendations. MMWR Rep. 2021. Available from: https://www.cdc.gov/vaccines/hcp/ acip-recs/vacc-specific/covid-19.html.

20 Infectious Diseases Society of America. Realtime learning network: vaccines FAQ. 2021. Available from: https://www.idsociety.org/ covid-19-real-time-learning-network/vaccines/vaccines-information--faq/.

21 American Society of Nephrology. Coronavirus disease 2019 (COVID-19). 2021. Available from: https://www.asn-online.org/covid-19/.

22 American College of Rheumatology. ACR updates: COVID-19 vaccine clinical guidance summary for patients with rheumatic and musculoskeletal diseases. 2021. Available from: https: //www.rheumatology.org/Announcements.

23 British Society for Immunology. A guide to vaccinations for COVID-19. 2021. Available from: https://www.immunology.org/publicinformation/guide-vaccinations-for-covid-19.
24 World Health Organization. Coronavirus disease (COVID-19): vaccines. 2021. Available from: https://www.who.int/emergencies/diseases/novel-coronavirus-2019/covid19-vaccines.

25 Holley JL. Immunizations in patients with end-stage kidney disease. In: Berns JS, editor. 2021. Accessed 2021 Jun 19.

26 Lisowska KA, Pindel M, Pietruczuk K, Kuźmiuk-Glembin I, Storoniak H, DębskaŚlizien A, et al. The influence of a single hemodialysis procedure on human T lymphocytes. Sci Rep. 2019;9(1):5041.

27 Edey M, Barraclough K, Johnson DW. Review article: hepatitis B and dialysis. Nephrology. 2010;15(2):137-45.

28 Broeders NE, Hombrouck A, Lemy A, Wissing KM, Racapé J, Gastaldello K, et al. Influenza $\mathrm{A} / \mathrm{H} 1 \mathrm{~N} 1$ vaccine in patients treated by kidney transplant or dialysis: a cohort study. Clin J Am Soc Nephrol. 2011;6(11):2573-8.

29 Rincon-Arevalo $\mathrm{H}$, Choi M, Stefanski AL, Halleck F, Weber U, Szelinski F, et al. Impaired humoral immunity to SARS-CoV-2 BNT162b2 vaccine in kidney transplant recipients and dialysis patients. Sci Immunol. 2021;6(60):eabj1031.

30 Anand S, Montez-Rath ME, Han J, Garcia P, Cadden LC, Hunsader P, et al. Antibody response to COVID-19 vaccination in patients receiving dialysis. J Am Soc Nephrol. 2021 Jun 11. Epub ahead of print.

31 Cohen DE, Sibbel S, Marlowe G, Bludorn K, Miller D, Kelley T, et al. Antibody status, disease history, and incidence of SARS-CoV-2 infection among patients on chronic dialysis. J Am Soc Nephrol. 2021;32(8):1880-6.

32 Pusey CD, Levy JB. Plasmapheresis in immunologic renal disease. Blood Purif. 2012;33(1): 190-8.

33 Ranganathan D, John GT. Therapeutic plasma exchange in renal disorders. Indian $\mathrm{J}$ Nephrol. 2019;29(3):151-9.

34 Guptill JT, Juel VC, Massey JM, Anderson AC, Chopra M, Yi JS, et al. Effect of therapeutic plasma exchange on immunoglobulins in myasthenia gravis. Autoimmunity. 2016; 49(7):472-9.

35 Patriquin CJ, Laroche V, Selby R, Pendergrast J, Barth D, Côté B, et al. Therapeutic plasma exchange in vaccine-induced immune thrombotic thrombocytopenia. N Engl J Med. 2021 Aug 26;385(9):857-9.

36 Putter JS, Seghatchian J. An update on COVID-19 infection control measures, plasmabased therapeutics, corticosteroid pharmacotherapy and vaccine research. Transfus Apher Sci. 2020;59(5):102934.

37 De Bosscher K, Schmitz ML, Vanden Berghe W, Plaisance S, Fiers W, Haegeman G. Glucocorticoid-mediated repression of nuclear factor-kappaB-dependent transcription involves direct interference with transactivation. Proc Natl Acad Sci U S A. 2000;94(25):13504-9.
38 Ponticelli C, Locatelli F. Glucocorticoids in the treatment of glomerular diseases: pitfalls and pearls. Clin J Am Soc Nephrol. 2018; 13(5):815-22.

39 Byrnes JW, Bhutta AT, Rettiganti MR, Gomez A, Garcia X, Dyamenahalli U, et al. Steroid therapy attenuates acute phase reactant response among children on ventricular assist device support. Ann Thorac Surg. 2015;99(4): 1392-8.

40 Park A, Iwasaki A. Type I and type III interferons: induction, signaling, evasion, and application to combat COVID-19. Cell Host Microbe. 2020;27(6):870-8.

41 Fauci AS, Dale DC. The effect of in vivo hydrocortisone on subpopulations of human lymphocytes. J Clin Invest. 1974;53(1):240-6.

42 Chakravarthy K, Strand N, Frosch A, Sayed D, Narra LR, Chaturvedi R, et al. Recommendations and guidance for steroid injection therapy and COVID-19 vaccine administration from the American Society of Pain and Neuroscience (ASPN). J Pain Res. 2021;14:623-9.

43 Ranjan P, Chakrawarty A, Kumari A, Kumar J. Immunization in patients with rheumatic diseases: a practical guide for general practitioners. J Clin Diagn Res. 2015;9(5):OE01-4.

44 Marinaki S, Tsiakas S, Liapis G, Skalioti C, Kapsia E, Lionaki S, et al. Clinicopathologic features and treatment outcomes of patients with fibrillary glomerulonephritis: a case series. Medicine. 2021;100(20):e26022.

45 Brocato RL, Principe LM, Kim RK, Zeng X, Williams JA, Liu Y, et al. Disruption of adaptive immunity enhances disease in SARSCoV-2-infected Syrian hamsters. J Virol. 2020;94(22): e01683-20.

46 Sitsigu A, Viaud S, Chaput N, Bracci L, Proietti E, Zitvogel L. Immunomodulatory effects of cyclophosphamide and implementations for vaccine design. Semin Immunopath. 2011; 33(4):369-82.

47 Ahlmann M, Hempel G. The effect of cyclophosphamide on the immune system: implications for clinical cancer therapy. Cancer Chemother Pharmacol. 2016;78(4):661-71.

48 Broen JCA, van Laar JM. Mycophenolate mofetil, azathioprine and tacrolimus: mechanisms in rheumatology. Nat Rev Rheumatol. 2020;16:167-78.

49 Keshtkar-Jahromi M, Argani H, Rahnavardi M, Mirchi E, Atabak S, Tara SA, et al. Antibody response to influenza immunization in kidney transplant recipients receiving either azathioprine or mycophenolate: a controlled trial. Am J Nephrol. 2008;28(4):654-60.

50 Boyarsky BJ, Ruddy JA, Connolly CM, Ou MT, Werbel WA, Garonzik-Want JM, et al. Antibody response to a single dose of SARSCoV-2 mRNA vaccine in patients with rheumatic and musculoskeletal diseases. Ann Rheum Dis. 2021 Mar 23. Epub ahead of print.

51 Mori S, Ueki Y, Hirakata N, Oribe M, Hidaka $\mathrm{T}$, Oishi K. Impact of tocilizumab therapy on antibody response to influenza vaccine in patients with rheumatoid arthritis. Ann Rheum Dis. 2012;71:2006-10.
Immunosuppression and SARS-CoV-2 Vaccines in Glomerular Diseases
Glomerular Dis 2021;1:277-293 
52 Gabay C, Bel M, Combescure C, Ribi C, Meier S, Posfay-Barbe K, et al. Impact of synthetic and biologic disease-modifying antirheumatic drugs on antibody responses to the AS03-adjuvanted pandemic influenza vaccine: a prospective, open-label, parallel-cohort, single-center study. Arthritis Rheum. 2011;63:1486-96.

53 Park JK, Lee YJ, Bitoun S, Winthrop KL, Choi $\mathrm{Y}$, Lee EB, et al. Interaction between B-cell activation factor and methotrexate impacts immunogenicity of seasonal influenza vaccination in patients with rheumatoid arthritis. Ann Rheum Dis. 2019;78(2):282-4.

54 Migita K, Akeda Y, Akazawa M, Tohma S, Hirano F, Ideguchi $\mathrm{H}$, et al. Pneumococcal polysaccharide vaccination in rheumatoid arthritis patients receiving tacrolimus. Arthritis Res Ther. 2015;17:149.

55 Boyarsky BJ, Werbel WA, Avery RK, Tobian AAR, Massie AB, Segev DL, et al. Antibody response to 2-dose SARS-CoV-2 mRNA vaccine series in solid organ transplant recipients. JAMA. 2021;325(21):2204-6.

56 Willcocks LC, Chaudhry AN, Smith JC, Ojha S, Doffinger R, Watson CJ, et al. The effect of sirolimus therapy on vaccine responses in transplant recipients. Am J Transplant. 2007; 7:2006-11.

57 Bingham CO 3rd, Looney RJ, Deodhar A, Halsey N, Greenwald M, Codding C, et al. Immunization responses in rheumatoid arthritis patients treated with rituximab: results from a controlled clinical trial. Arthritis Rheum. 2010;62(1):64-74.

58 Sattler A, Schrezenmeier E, Weber UA, Potekhin A, Bachmann F, Straub-Hohenbleicher $\mathrm{H}$, et al. Impaired humoral and cellular immunity after SARS-CoV-2 BNT162b2 (tozinameran) prime-boost vaccination in kidney transplant recipients. medRxiv. 2021;131(14): e150175.

59 Benotmane I, Gautier-Vargas G, Cognard N Olagne J, Heibel F, Braun-Parvez L, et al. Weak anti-SARS-CoV-2 antibody response after the first injection of an mRNA COVID-19 vaccine in kidney transplant recipients. Kidney Int. 2021;99(6):1487-9.

60 Lin YC, Winokur P, Blake A, Wu T, Manischewitz J, King LR, et al. Patients with MS under daclizumab therapy mount normal immune responses to influenza vaccination. Neurol Neuroimmunol Neuroinflamm. 2016 Jan; 3(1):e196

61 Hequet D, Pascual M, Lartey S, Pathirana RD, Bredhold G, Hoschler K, et al. Humoral, Tcell and B-cell immune responses to seasonal influenza vaccine in solid organ transplant recipients receiving anti-T cell therapies. Vaccine. 2016;34(31):3576-83

62 Bange EM, Han NA, Wileyto P, Kim JY, Gouma S, Robinson J, et al. CD8 T cells compensate for impaired humoral immunity in COVID-19 patients with hematologic cancer. Res Sqr [Preprint]. 2021.
63 Wallin EF, Hill DL, Linterman MA, Wood KJ. The calcineurin inhibitor tacrolimus specifically suppresses human $\mathrm{T}$ follicular helper cells. Front Immunol. 2018;9:1184.

64 Turner AP, Shaffer VO, Araki K, Martens C, Turner PL, Gangappa S, et al. Sirolimus enhances the magnitude and quality of viralspecific $\mathrm{CD} 8+\mathrm{T}$-cell responses to vaccinia virus vaccination in rhesus macaques. Am J Transplant. 2011;11(3):613-8.

65 Mannick JB, Del Giudice G, Lattanzi M, Valiante NM, Praestgaard J, Huang B, et al. mTOR inhibition improves immune function in the elderly. Sci Transl Med. 2014;6: 268 ra179.

66 Boslett B, McKenzie S; on behalf of the Vaccine Working Group on Immunocompromised and Special Populations. Vaccine guidelines IC-special populations. San Francisco: University of California, San Francisco; 2021. Accessed 2021 Jun 19.

67 Morandi F, Horenstein AL, Costa F, Giuliani N, Pistoia V, Malavasi F. CD38: a target for immunotherapeutic approaches in multiple myeloma. Front Immunol. 2018;9:2722.

68 Zambello R, Barilà G, Manni S, Piazza F, Semenzato G. NK cells and CD38: implication for (immuno) therapy in plasma cell dyscrasias. Cells. 2020;9(3):768.

69 Sandoval-Montes C, Santos-Argumedo L. CD38 is expressed selectively during the activation of a subset of mature $T$ cells with reduced proliferation but improved potential to produce cytokines. J Leukoc Biol. 2005;77(4): 513-21.

70 Frerichs KA, Bosman PWC, van Velzen JF, Fraaij PLA, Koopmans MPG, Rimmelzwaan GF, et al. Effect of daratumumab on normal plasma cells, polyclonal immunoglobulin levels, and vaccination responses in extensively pre-treated multiple myeloma patients. Haematologica. 2020;105:e302.

71 Terpos E, Trougakos IP, Gavriatopoulou M, Papassotiriou I, Sklirou AD, Ntanasis-Stathopoulos I, et al. Low neutralizing antibody responses against SARS-CoV-2 in elderly myeloma patients after the first BNT162b2 vaccine dose. Blood. 2021 Jul 1;137(26):3674-6.

72 Ramwadhdoebe TH, van Baarsen LGM, Boumans MJH, Bruijnen STG, Safy M, Berger FH, et al. Effect of rituximab treatment on $\mathrm{T}$ and $\mathrm{B}$ cell subsets in lymph node biopsies of patients with rheumatoid arthritis. Rheumatology. 2019;58(6):1075-85.

73 Cree BAC, Bennett JL, Kim HJ, Weinshenker BG, Pittock SJ, Wingerchuk DM, et al. Inebilizumab for the treatment of neuromyelitis optica spectrum disorder (NMOmentum): a double-blind, randomized placebo-controlled phase 2/3 trial. Lancet. 2019; 394(10206):1352-63.

74 Melet J, Mulleman D, Goupille P, Ribourtout B, Waiter H, Thibault G. Rituximab-induced $\mathrm{T}$ cell depletion in patients with rheumatoid arthritis: association with clinical response. Arthritis Rheum. 2013;65(11):2783-90.
75 Neel A, Bucchia M, Neel M, Tilly G, Caristan A, Yap M, et al. Dampening of CD8+ T cell response by $\mathrm{B}$ cell depletion therapy in antineutrophil cytoplasmic antibody-associated vasculitis. Arthritis Rheum. 2019 Apr;71(4): 641-50.

76 Bar-Or A, Calkwood JC, Chognot C, Evershed J, Fox EJ, Herman A, et al. Effect of ocrelizumab on vaccine responses in patients with multiple sclerosis: the VELOCE study. Neurology. 2020;95:e1999-2008.

77 Kim W, Kim SH, Huh SY, Kong SY, Choi YJ, Cheong HJ, et al. Reduced antibody formation after influenza vaccination in patients with neuromyelitis optica spectrum disorder treated with rituximab. Eur J Neurol. 2013; 20(6):975-80.

78 Kant S, Kronbichler A, Salas A, Bruchfeld A, Geetha D. Timing of COVID-19 vaccine in the setting of anti-CD20 therapy: a primer for nephrologists. Kidney Int Rep. 2021 May; 6(5):1197-9.

79 Lamure S, Dulery R, Delord M, Di Blasi R, Chauchet A, Hueso T, et al. High incidence of persistent COVID-19 among patients with lymphoma treated with B-cell depleting immunotherapy. Am Assoc Canc Res. 2021 Mar 21;27(Suppl 6):Abstract S09-02.

80 Jayne DRW, Merkel PA, Schall TJ, Bekker P. Avacopan for the treatment of ANCA-associated vasculitis. N Engl J Med. 2021;384(7): 599-609.

81 Bekker P, Dairaghi D, Seitz L, Leleti M, Wang Y, Erti L, et al. Characterization of pharmacologic and pharmacokinetic properties of CCX168, a potent and selective orally administered complement $5 \mathrm{a}$ receptor inhibitor, based on preclinical evaluation and randomized phase 1 clinical study. PLoS One. 2016 Oct 21;11(10):e0164646.

82 Haas L, Wang F. Study of the safety and efficacy of OMS721 in patients with immunoglobulin A (IgA) nephropathy. 2021 ClinicalTrials.gov identifier NCT03608033.

83 Mulling N, Rohn H, Vogel U, Claus H, Wilde B, Eisenberger U, et al. Low efficacy of vaccination against serogroup $B$ meningococci in patients with atypical hemolytic uremic syndrome. Biosci Rep. 2020;40(3):BSR20200177.

84 Gackler A, Kaulfub M, Rohn H, Vogel U, Claus H, Feldkamp T, et al. Failure of first meningococcal vaccination in patients with atypical haemolytic uraemic syndrome treated with eculizumab. Nephrol Dial Transpl. 2020;35(2):298-303.

85 Alashkar F, Vance C, Herich-Terhürne D, Preising N, Dührsen U, Röth A. Serologic response to meningococcal vaccination in patients with paroxysmal nocturnal hemoglobinuria $(\mathrm{PNH})$ chronically treated with the terminal complement inhibitor eculizumab. Ann Hematol. 2017;96(4):589-96.

86 Benamu E, Montoya JG. Infections associated with the use of eculizumab: recommendations for prevention and prophylaxis. Curr Opin Infect Dis. 2016;29(4):319-29. 
87 Cohn AC, MacNeil JR, Clark TA, Ortega-Sanchez IR, Briere EZ, Meissner HC, et al. Prevention and control of meningococcal disease: recommendations of the Advisory Committee on Immunization Practices (ACIP). MMWR Recomm Rep. 2013;62(RR-2):1-28.

88 Navarrete JE, Tong DC, Cobb J, Rahbari-Oskoui FF, Hosein D, Caberto SC, et al. Epidemiology of COVID-19 Infection in hospitalized end-stage kidney disease patients in a predominantly African-American population. Am J Nephrol. 2021;52(3):190-8.

89 Bomback AS, Canetta PA, Ahn W, Ahmad SB, Radhakrishnan J, Appel GB. How COVID-19 has changed the management of glomerular diseases. Clin J Am Soc Nephrol. 2021;15(6):876-9.

90 Bomback AS, Kudose S, D’Agati VD. De novo and relapsing glomerlular diseases after $\mathrm{CO}$ VID-19 vaccination: what do we know so far? Am J Kid Dis. 2021 Jun 25. Epub ahead of print.

91 Werbel WA, Boyarsky BJ, Ou MT, Massie AB, Tobian AAR, Garonzik-Wang JM, et al. Safety and immunogenicity of a third dose of SARS-CoV-2 vaccine in solid organ transplant recipients: a case series. Ann Intern Med. 2021 Jun 15. Epub ahead of print.
92 Oliver S. Data and clinical considerations for additional doses in immunocompromised people. US Centers for Disease Control and Prevention Advisory Committee on Immunization Practices. 2021. Available from: www. cdc.gov/vaccines/acip/meetings/downloads/ slides-2021-07/07-COVID-Oliver-508.pdf Accessed 2021 Jul 22

93 Kamar N, Abravanel F, Marion O, Couat C, Izopet J, Del Bello A. Three doses of an mRNA COVID-19 vaccine in solid organ transplant recipients. N Engl J Med. 2021 Aug 12;385(7): 661-2.

94 Espi M, Charmetant X, Barba T, Pelletier C, Koppe L, Chalencon E, et al. Justification, safety and efficacy of a third dose of mRNA vaccine in maintenance hemodialysis patients: a prospective observational study. medRxiv [Preprint]. 2021.

95 Callaway E. COVID vaccine boosters: the most important questions. Nature. 2021; 596(7871):178-80.

96 US Food and Drug Administration. Coronavirus (COVID-10) update: FDA authorizes additional vaccine dose for certain immunocompromised individuals. 2021. Available from: https: //www.fda.gov/news-events/ press-announcements/coronavirus-covid19-update-fda-authorizes-additional-vaccine-dose-certain-immunocompromised Released 2021 Aug 12.

97 Israel Councils for Health. 2021. Available from: www.govextra.gov.il/media/30095/ meeting-summary-15122020.pdf.
98 Advis du Conseil Scientifique COVID-19 (France). Reagir maintenant pour limiter une nouvelle vague associee au variant delta. 2021. Available from: www.solidarites-sante.gouv. fr/IMG/pdf/avis_conseil_scientifique_6_juillet_2021_actualise_8_juillet_2021.

99 National Health Service (United Kingdom). COVID-19 vaccination autumn/winter (phase 3) planning. 2021. Available from: www.england.nhs.uk/coronavirus/wp-content/uploads/sites/52/2021/07/C1327-covid-19-vaccination-autumn-winter-phase3-planning.pdf.

100 Department of Health and Social Care (United Kingdom). JCVI interim advice: potential COVID-19 booster vaccine programme winter 2021 to 2022. 2021. Available from: https: //www.gov.uk/government/publications/jcvi-interim-advice-on-a-potential-coronavirus-covid-19-booster-vaccine-programmefor-winter-2021-to-2022.

101 Roozen GVT, Prins MLM, van Binnendijk R, den Hartog G, Kuiper VP, Prins C, et al. Tolerability, safety and immunogenicity of intradermal delivery of a fractional dose mRNA-1273 SARS-CoV-2 vaccine in healthy adults as a dose-sparing strategy. medRxiv [Preprint]. 2021.

102 Hassan AO, Feldmann F, Zhao H, Curiel DT, Okumura A, Tang-Huau TL, et al. A single intranasal dose of chimpanzee adenovirus-vectored vaccine protects against SARS-CoV-2 infection in rhesus macaques. Cell Rep Med. 2021;2(4):100230. 